\title{
A propósito de Destino (2003), de Salvador Dalí y Walt Disney
}

\section{Basilio Casanova Varela}

\author{
Recibido: 3.04.2020 — Aceptado: 15.05.2020
}

\section{Title / Titre / Titolo}

On Destino, by Salvador Dalí and Walt Disney

À propos de Destino, de Salvador Dalí et Walt Disney

A proposito di Destino, di Salvador Dalí e Walt Disney

\section{Resumen / Abstract / Résumé / Riassunto}

Analizamos en este artículo la presencia, en el corto de animación Destino (2003), de algunos de los motivos plásticos más recurrentes en la obra de Salvador Dalí. Por él irán desfilando los relojes blandos, las muletas, la sensación de hormigueo y hasta la más fatídica o la más deseada de las horas. Procedemos a hacer un recuento de dichos motivos, aquí animados, y a darle un sentido a su presencia tanto en el corto como, por extensión, en la obra del pintor de Figueras.

In this article we analyse the presence, in the animated short film Destino (2003), of some of the most recurrent plastic motifs in Salvador Dalís work. The soft watches, the crutches, the tingling sensation and even the most fateful or most desired hours will be paraded through it. We shall proceed to recount these motifs, animated in the short, and to give a sense of their presence both in the short film and, by extension, in the work of the painter from Figueres.
Dans cet article, nous analysons la présence, dans le court-métrage d'animation Destino (2003), de certains des motifs plastiques les plus récurrents dans l'œuvre de Salvador Dalí. Les montres douces, les béquilles, la sensation de picotement et même les heures les plus fatidiques ou les plus désirées y défileront. Nous allons maintenant procéder à la narration de ces motifs, ici animés, et donner une idée de leur présence à la fois dans le court métrage et, par extension, dans l'œuvre du peintre de Figueres.

In questo articolo analizziamo la presenza, nel cortometraggio animato Destino (2003), di alcuni dei motivi plastici più ricorrenti nell'opera di Salvador Dalí. Gli orologi morbidi, le stampelle, il formicolio e anche la più fatidica o la più desiderata delle ore verranno fatti sfilare. Procederemo trattare questi motivi, animati nel cortometraggio, e a dare un senso alla loro presenza tanto nel testo filmico, come, per estensione, nell'opera dell'artista di Figueres.

\section{Palabras clave / Keywords I Mots-clé / Parole chiave}

Destino, hormigueo, relojes blandos, Dalí, Walt Disney.

Destino, tingling, soft clocks, Dalí, Walt Disney.

Destino, fourmillements, montres douces, Dalí, Walt Disney.

Destino, pizzicore, orologi morbidi, Dalí, Walt Disney. 


\section{Introducción: Salvador Dalí}

Salvador Dalí, como Vicent van Gogh, llevaba el nombre de un muerto. Su hermano mayor, Salvador, murió nueve meses antes de nacer el pintor.

A la edad de cinco años, los padres condujeron a Dalí hasta la tumba de su hermano y le dijeron que él era su reencarnación.

Salvador Felipe Jacinto Dalí nació el 11 de mayo de 1904 en Figueras. Dalí dijo de su hermano: «nos parecíamos como dos gotas de agua, pero dábamos reflejos diferentes... Mi hermano era probablemente una primera visión de mí mismo...» (Dalí, 2).

\section{Destino}

Una mujer se aproxima hasta un gran monumento de mármol con forma de pirámide en el que se dibuja, en altorrelieve, la figura de un guerrero, quizá un gladiador, que apoya su mano izquierda sobre un reloj-escudo sostenido por la cabeza de Medusa.

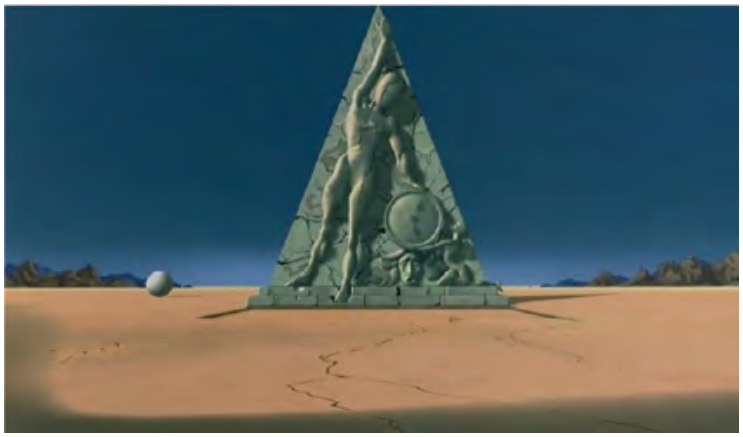

Podría tratarse también de Cronos, el dios del tiempo.

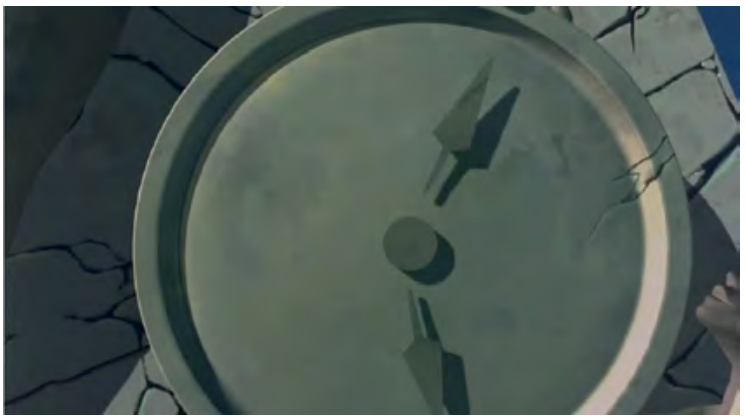

Un gran primer plano muestra en detalle el escudoreloj. No hay números, pero se puede leer en él la hora: las cinco y cinco. Las aguja superior y la inferior, inclinadas ambas hacia la derecha, son simétricas, y las dos proyectan sobre el fondo una sombra que las hace desdoblarse o duplicarse.

Dalí: «nos parecíamos como dos gotas de agua, pero dábamos reflejos diferentes».

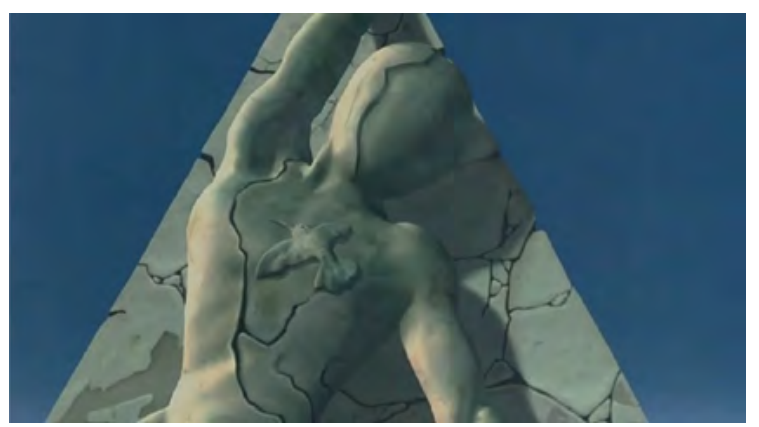

El agrietado gladiador del tiempo, una suerte de daliniano Saturno, carece de rostro y en su pecho lleva esculpido un colibrí.

Se diría un ser yacente, tendido sobre un lecho tan marmóreo y agrietado como él mismo.

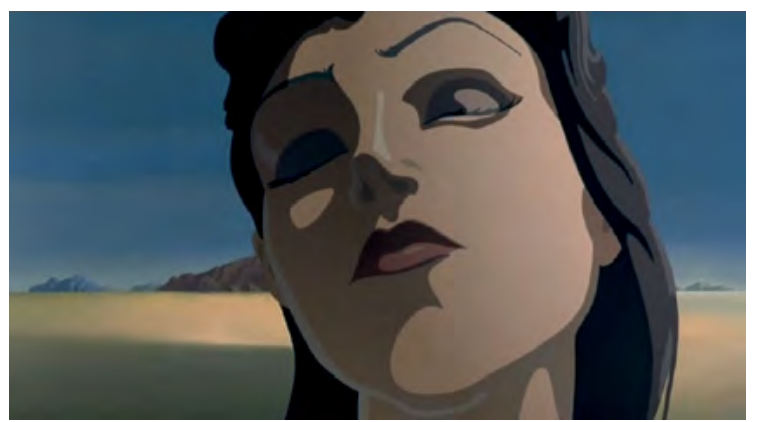

La mujer, en cambio, tiene rostro y éste es, además, gigantesco. De perfiles suaves y delicados, situada a los pies del monumento, termina por cerrar los ojos, como si estuviese soñando.

Ha salido la luna y la mujer brilla ahora inmensa en medio de la noche.

Primero abraza el monumento y después, como si estuviese hecho de plastilina, lo hace desaparecer entre sus manos. 

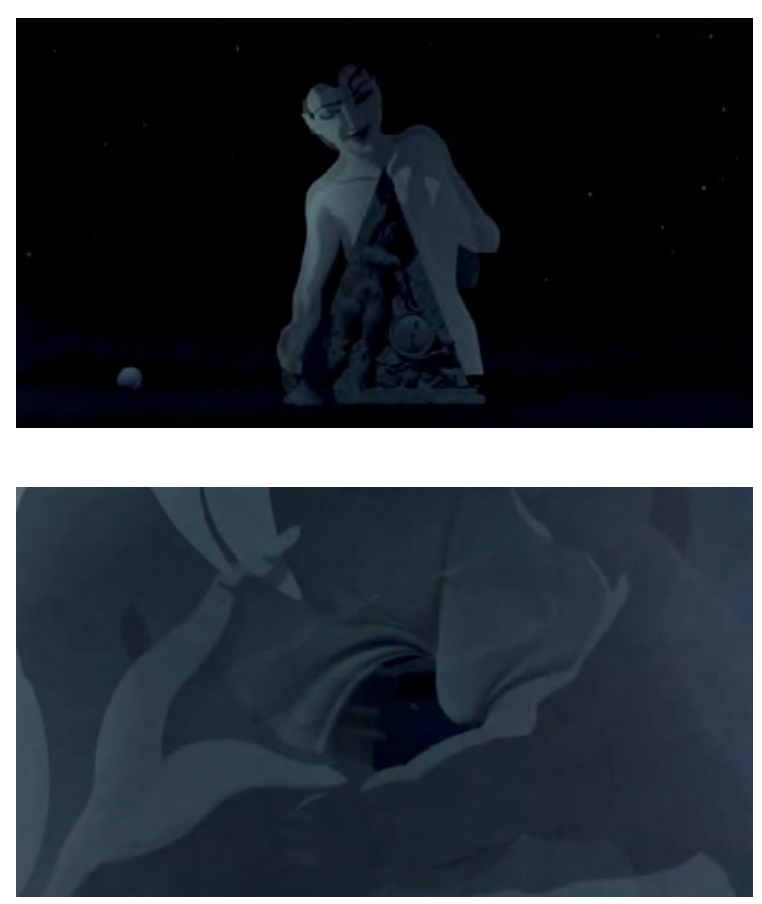

El corazón de la mujer se abre y en su interior tiene lugar la escena que sigue.

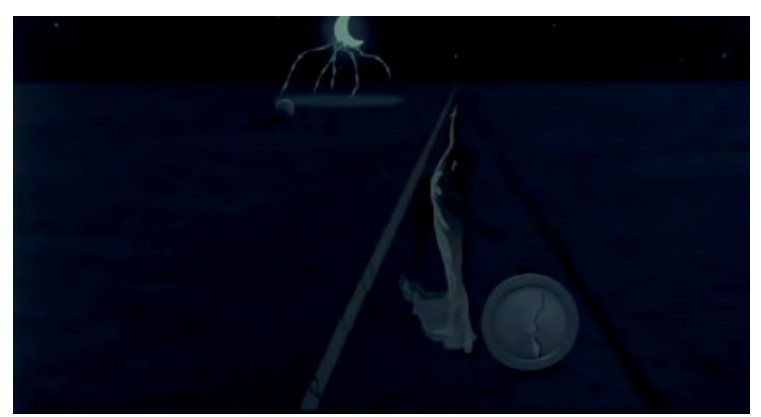

Al lado de la mujer, la esfera de un reloj, situados ambos sobre una especie de vía de tren; una composición que recuerda a la de Osificación prematura de una estación (1923).

Al fondo vemos la luna, en su fase menguante, con patas de araña; cerca de ella una esfera. Siguen siendo las cinco y cinco.

El reloj de Osificación prematura de una estación marca una hora distinta a la de Destino: las siete menos cinco. En ella el rostro de un hombre parece esconderse
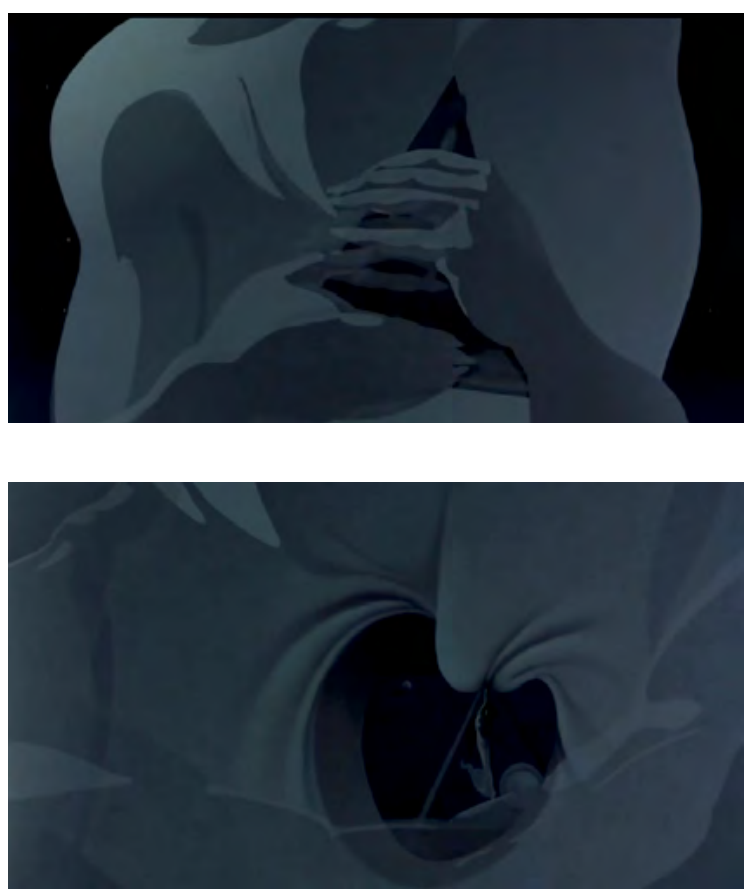

detrás del reloj blando de una estación, como reza el propio título de la obra, prematuramente muerta.

Faltan en la esfera del reloj de esa estación, dos números: el once y el cinco. Salvador Dalí nació el día once del mes cinco del año 1904. Se trata de una estación de tren, pero una estación es también un período del año, relativo pues al tiempo o a la edad.

Fue a los cinco años cuando los padres le dijeron a Dalí que era la reencarnación de su hermano muerto.

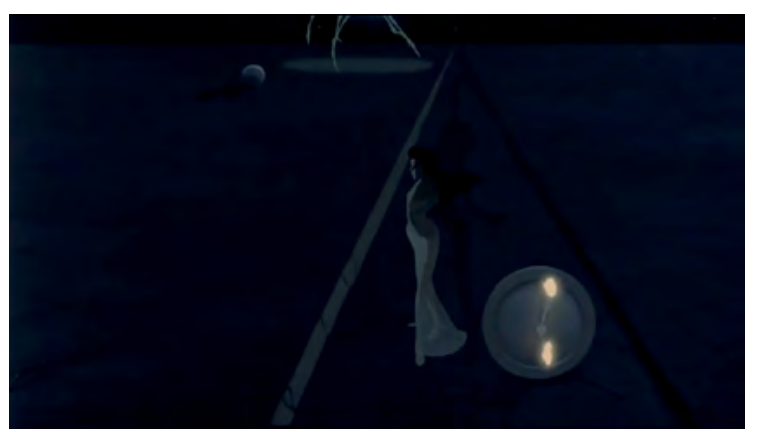

Las puntas de las agujas del reloj se han encendido como se encienden unas velas. La hora sigue siendo sin embargo la misma: las cinco y cinco. 


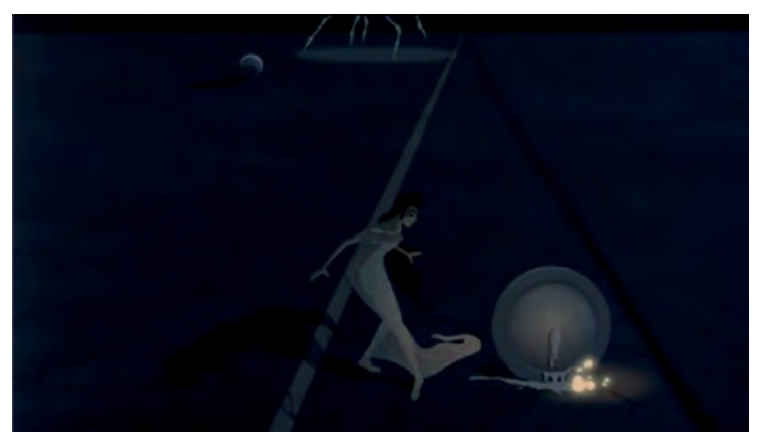

Las agujas del reloj se han derretido, ante la sorpresa de la mujer, como si fuesen de cera.

¿Qué hora marca el reloj en ese instante? Podríamos decir que ninguna, pero, igualmente, que las seis y media. Esa hora en la que las dos manecillas cuelgan señalando hacia abajo.

La hora más opuesta posible a las doce, la hora del Ángelus.

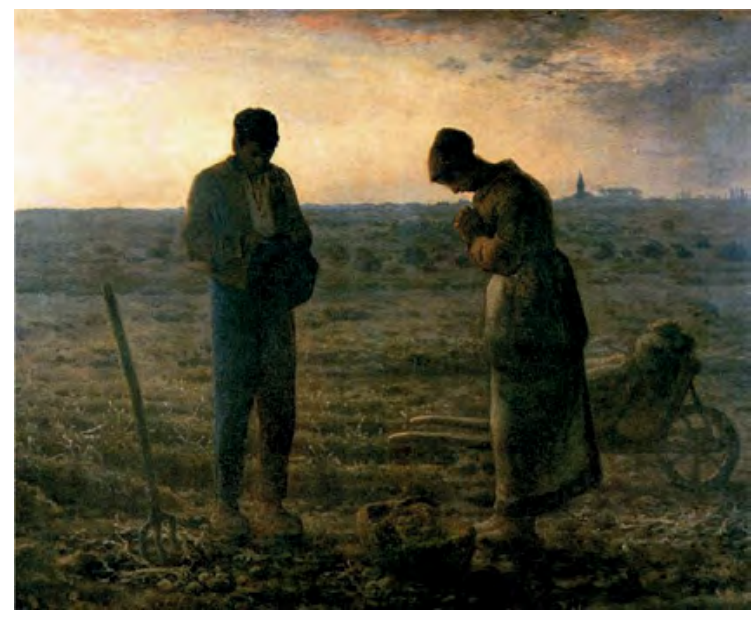

El Ángelus, de Millet.

Sabemos de la obsesión de Dalí por esta obra de Millet. Estaba convencido de que a esa hora en la que un ángel anunció a María que iba a concebir un hijo, Millet había pintado un niño muerto enterrado debajo de la cesta que hay a los pies de la mujer.

Ninguna hora más opuesta, pues, a la del Ángelus - que es también, no lo olvidemos, la de la Anunciación-, que la que marca en estos instantes el reloj de Destino.
De ahí quizá el gesto de espanto de la mujer, que saldrá huyendo inmediatamente de esa vía, muerta — sin anuncio posible_- y de esa hora, las seis y media, en la que las agujas cuelgan derretidas.

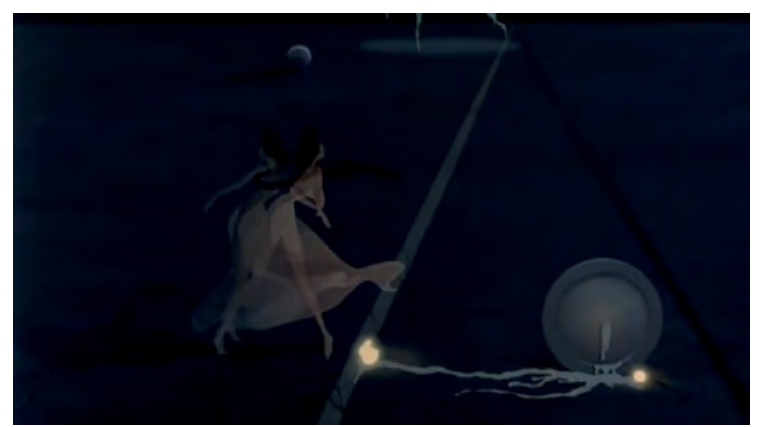

En su huida, la mujer se topa con el rostro de un hombre visto de perfil que, cuando está a punto de besar en los labios — aunque ni siquiera estos llegan a tocarse-
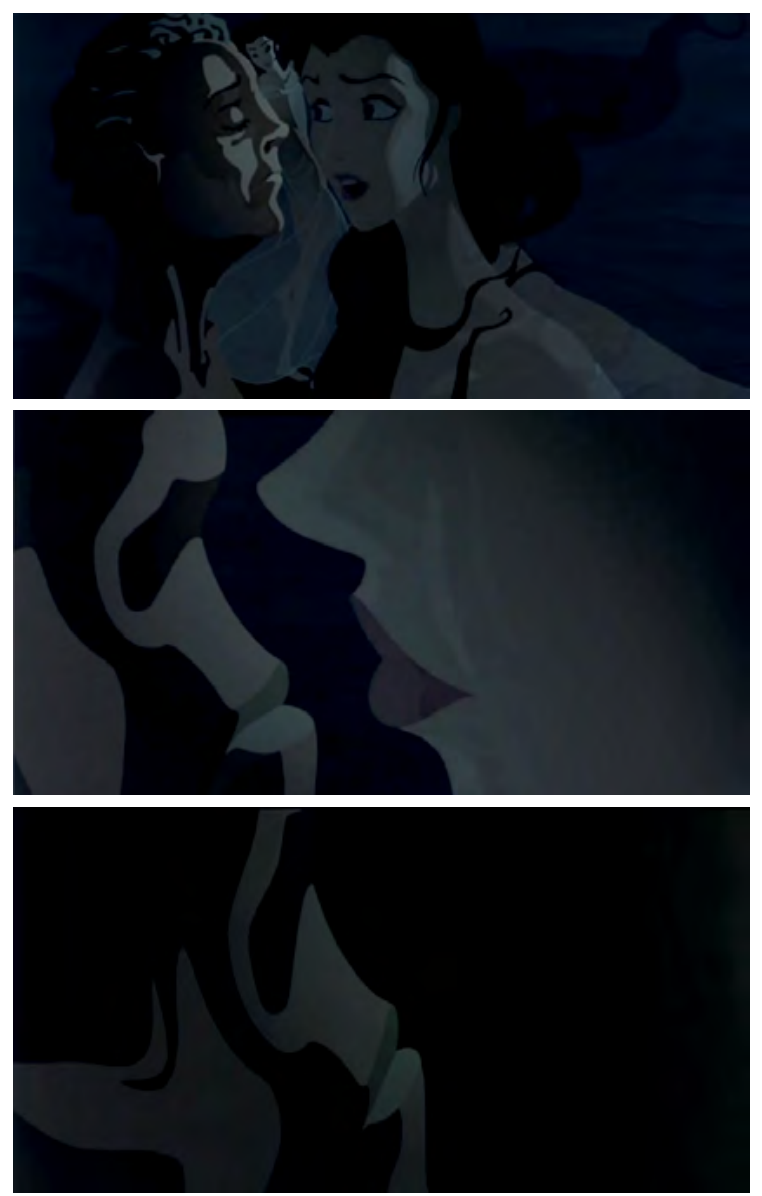
comienza también a derretirse, como se derretían las manecillas del reloj.

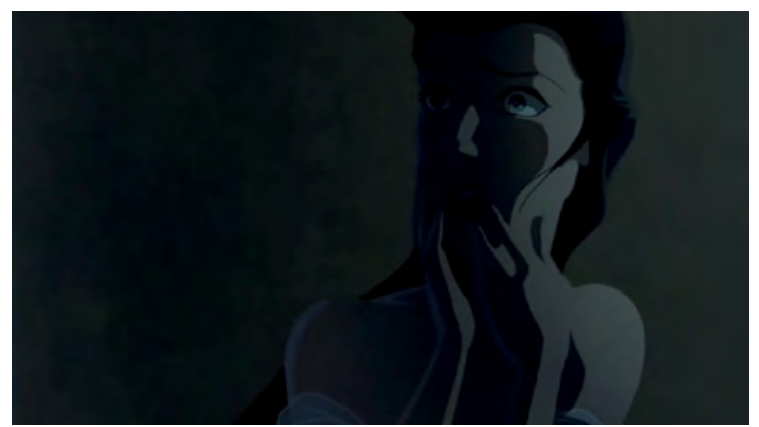

La cara de ella es de estupefacción y desconcierto. El rostro de él se convierte, así, en un rostro blando.

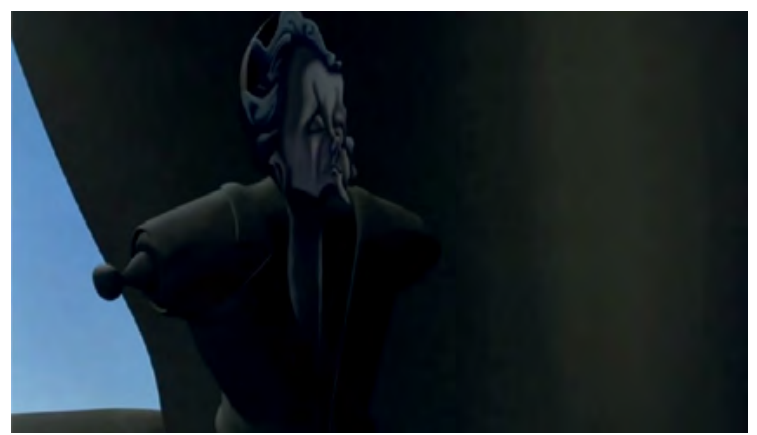

Tan blando como los relojes blandos de Dalí. Los de La persistencia de la memoria, por ejemplo.

Derretido el rostro, lo único que queda es un maniquí que parece salido de un cuadro de Giorgio de Chirico.

Un maniquí necesitado incluso de muletas y al que la mujer, decepcionada, acaba por ignorar.

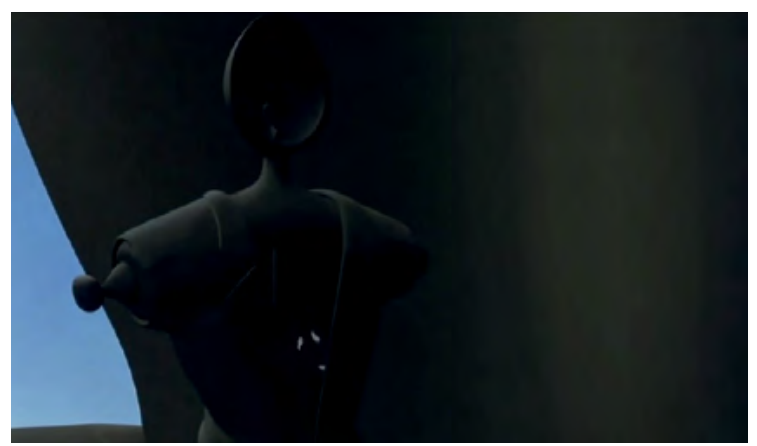

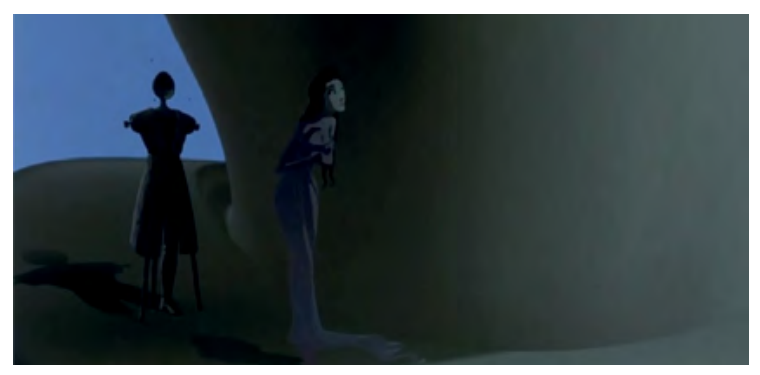

Ella y él, convertido en maniquí, se hallan a los pies de una gigantesca y femenina figura por la que enseguida veremos ascender a la mujer.

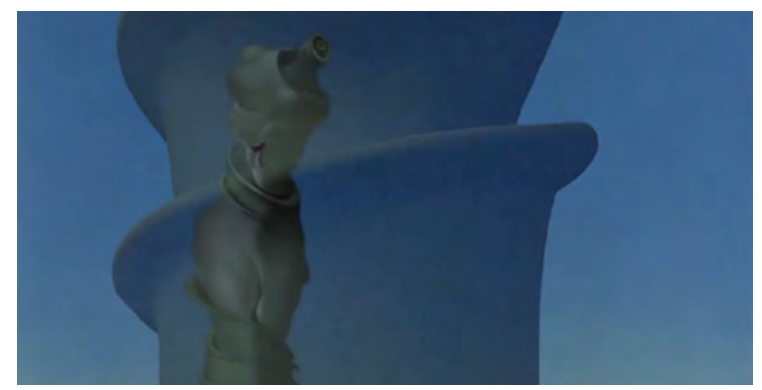

Durante el ascenso, ella se topará con esto:

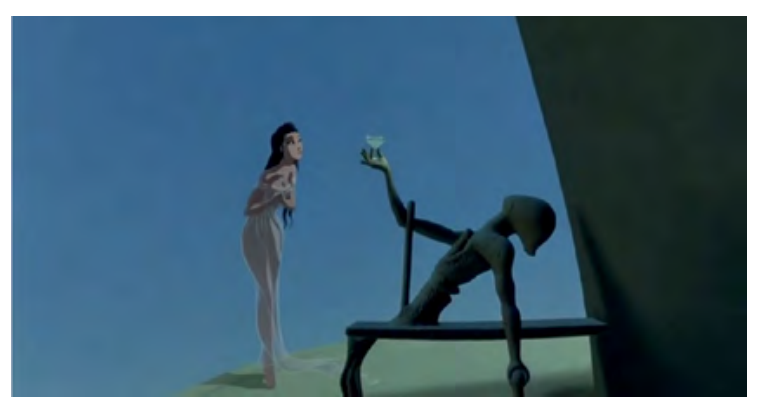

Algo se yergue, vertical, a la altura de la zona genital de esa figura masculina que parece estar a punto de realizar un brindis.

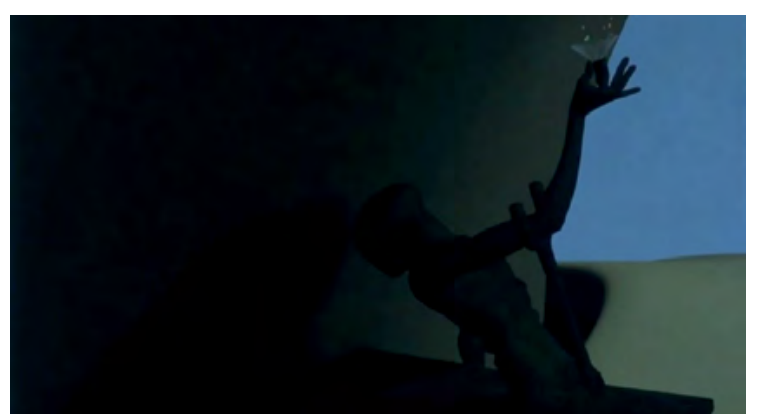


Se trata, claro está, de una muleta que es lo que sostiene y hace de apoyo al delicado brazo de la figura.

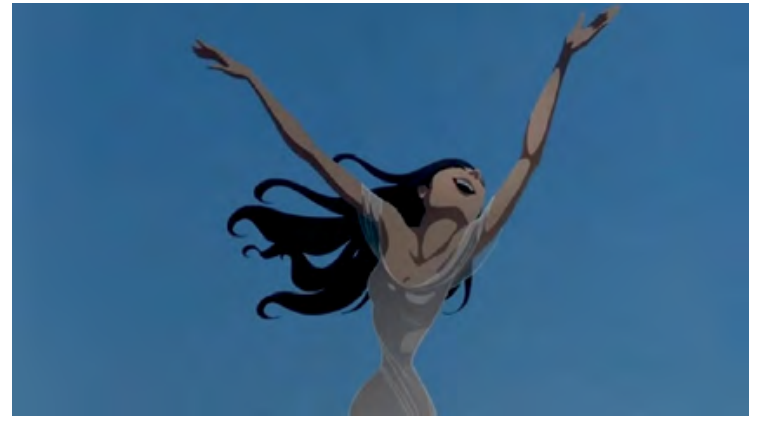

La mujer, ahora, parece feliz. Sus brazos trazan por momentos la forma también de una copa.

La mujer asciende hasta lo más alto de la colosal figura, desde la que se lanzará al vacío.

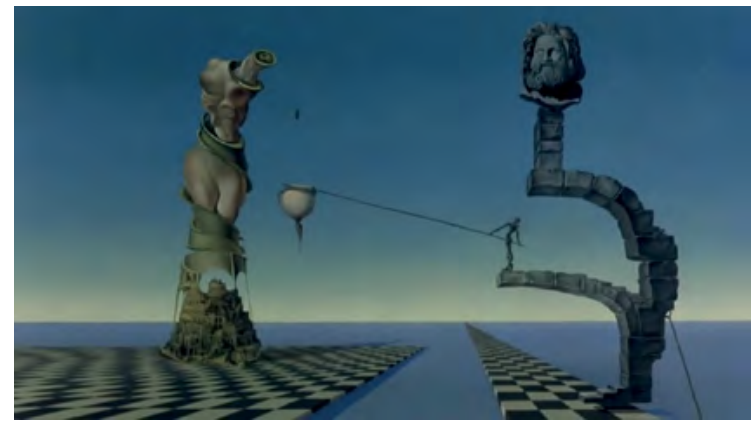

En realidad son dos las figuras. La de ella, una suerte de gran torre de Babel inspirada en la obra de Brueghel el viejo, no tiene cabeza; es toda ella cuerpo.

La de él, en cambio, tiene una cabeza como la de Zeus, y un cuerpo que necesita de una muleta que lo sostenga; tal es su inestabilidad.

Los caminos de ambas figuras son del todo divergentes. No hay contacto alguno entre ellas, y eso a pesar de la larga vara que sostiene en sus manos, impotente, la diminuta figura que se apoya en uno de las piedras que sobresalen del cuerpo, con forma de interrogación, de Zeus.

Podría tratarse también de las piezas de la Reina y el Rey de un imposible tablero de ajedrez.

La mujer, decíamos, se lanza al vacío y cae sobre un auricular de teléfono.
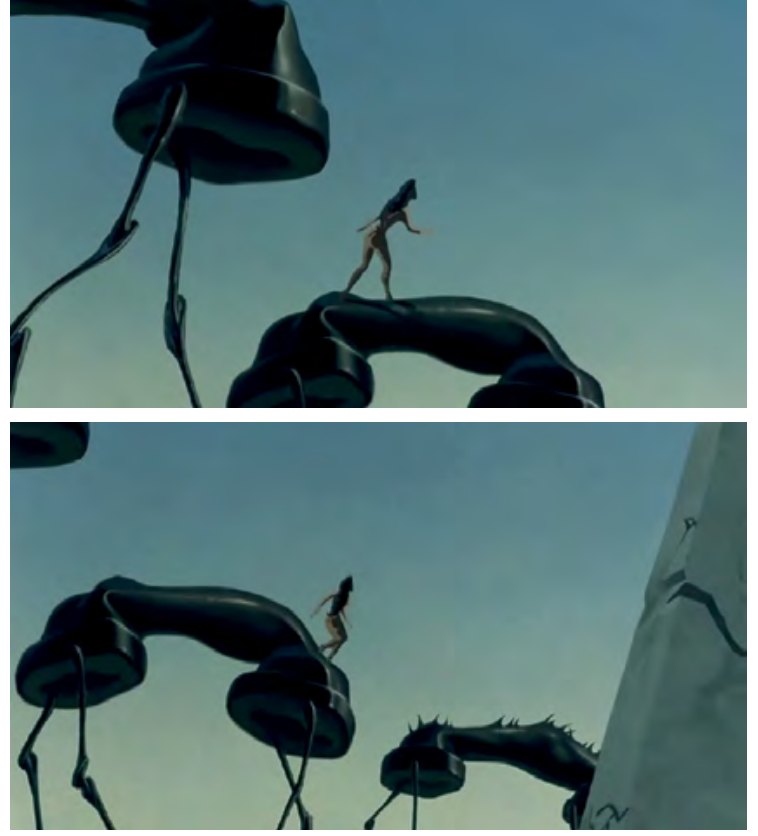

Los teléfonos tienen forma de hormiga y sobre ellos camina la mujer. Son casi idénticos al teléfono de El momento sublime, de 1938.

En ese que debería ser el más inolvidable, por sublime, de los momentos, un caracol con el cuerpo extremadamente blando trata de acercarse, inútilmente, a un auricular roto que cuelga de un árbol seco. En una sartén flotan dos huevos fritos. El mango de la sartén, que cuelga blando — derretido—-, es sostenido por una muleta; cerca se halla la presencia amenazante de una cuchilla de afeitar. Todo ello en un paisaje tan desértico como el de Destino.

Volvemos al monumento de Cronos, cuya cabeza sin rostro, al estilo metafísico de De Chirico, es mostrada ahora en un plano cercano.

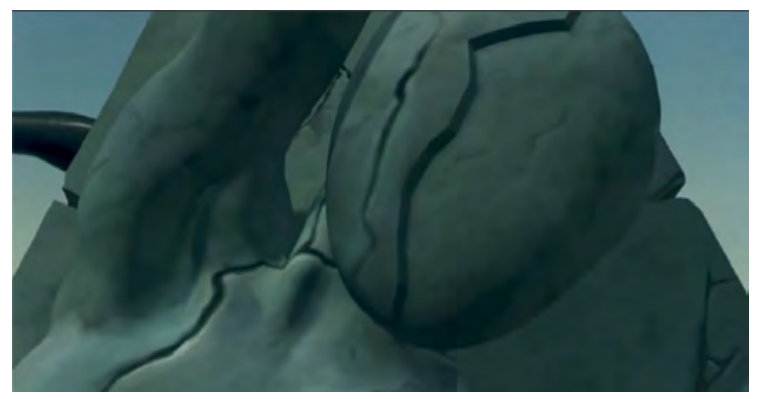




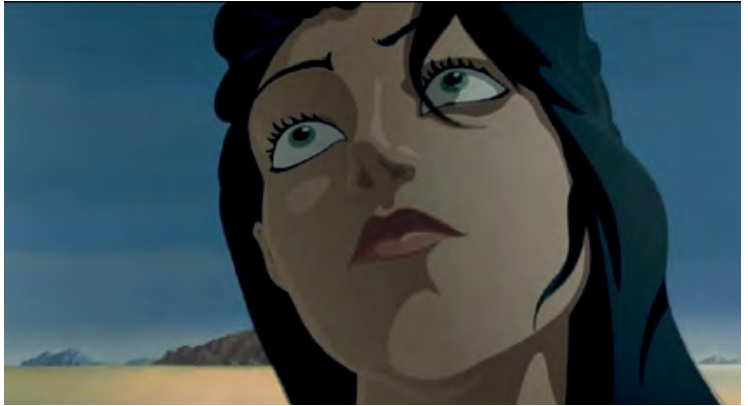

Se hace de nuevo presente el contraste, a través del plano/contraplano, entre el rostro humano de ella y la ausencia del mismo en él.

El altorrelieve parece despegarse de la lápida de mármol a la que se encontraba fijado.

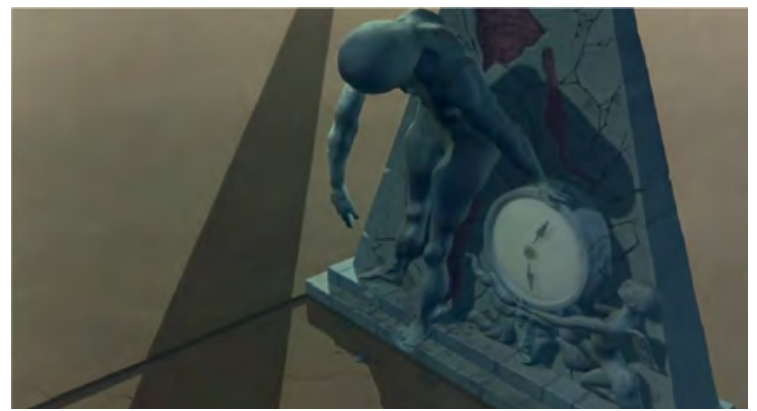

El reloj sigue marcando, inmutable e inexorablemente, las cinco y cinco.

La figura cobra vida y el reloj se ilumina como lo hace la luna en el cielo de la noche.

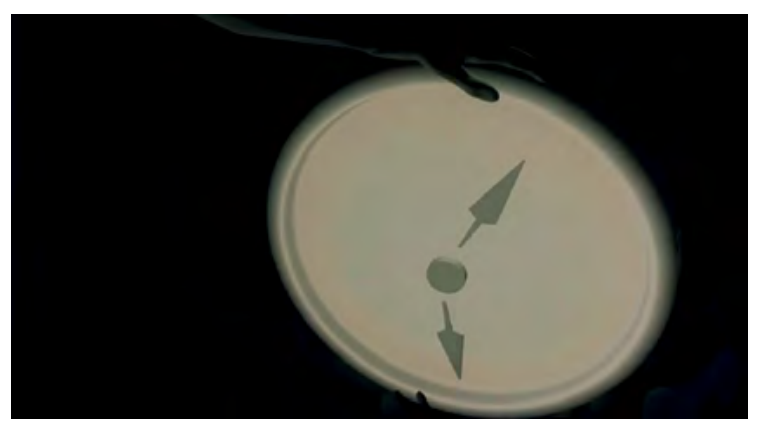

En esa hora - las cinco y cinco- late siempre en Dalí la amenaza de otra hora: la de las seis y media. Ya sabemos: el reverso mismo del Ángelus. El momento, angustioso, en que las agujas se derriten.
Este, sin embargo, no es todavía un reloj blando.

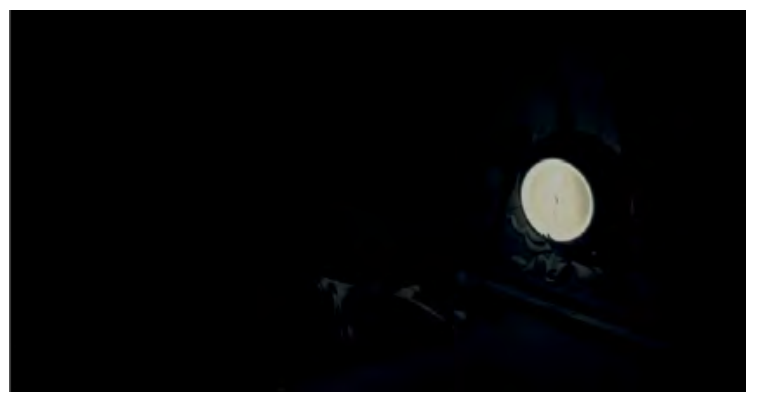

La estatua se desprende finalmente de esa pared triangular, y cae al suelo. El reloj marca, iluminado, la hora de la caída. Y deviene a continuación un reloj derretido, incapaz de marcar ya hora alguna. Nos encontramos ante una suerte de clímax, de momento culmen.
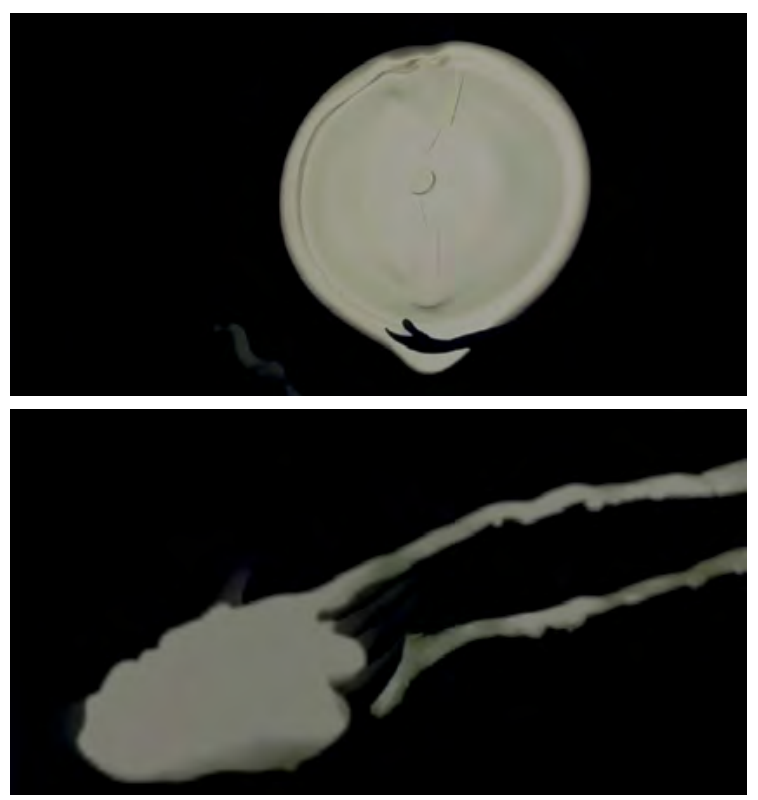

Reloj y figura se dan ahora la mano.

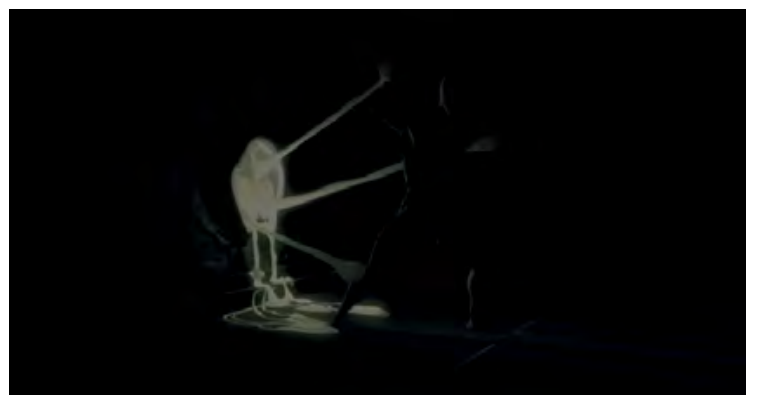


Las manecillas se han convertido en una sustancia gelatinosa —de ecos espermáticos- que impide a nuestro heroico gladiador alejarse de esa lápida que hacía de él una figura no exenta, aunque sí de alto relieve.

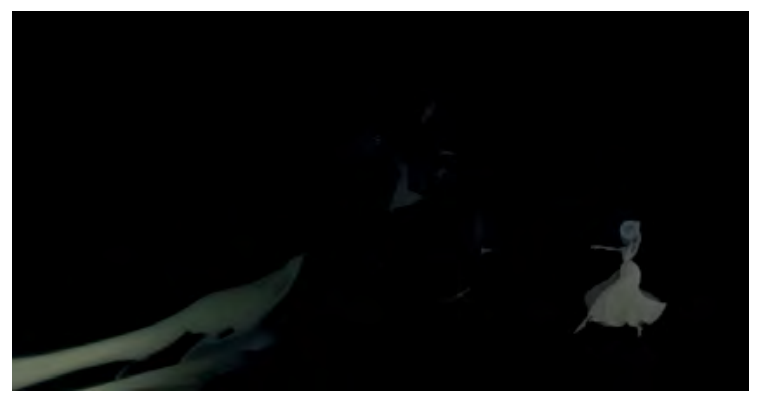

Un ser atrapado que, a pesar de que lo intenta con todas sus fuerzas, no consigue acercarse a esa mujer cuya cabeza se ha convertido, por arte de magia, en «diente de león».

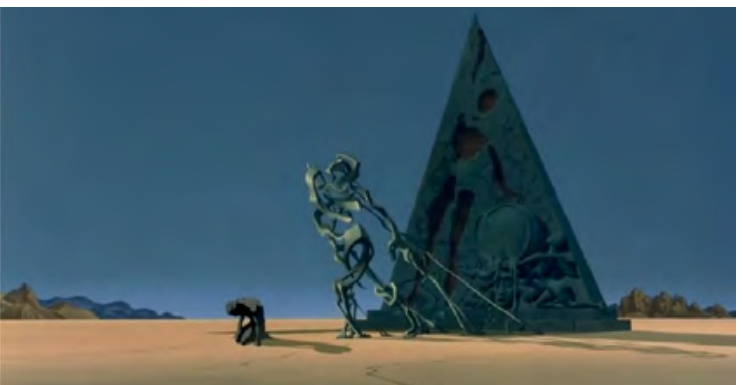

Su destino, el destino de él, está escrito: no podrá despegarse ni de ese lugar ni de ese tiempo en el que parece estar detenido para siempre.

Medusa muestra, así, todo su poder petrificador. Ahí está, convertida ella misma en reloj, o el reloj convertido en cabeza de Gorgona.

$\mathrm{Y}$, sin embargo, todavía es posible en Destino el color, el latido, el pulso.

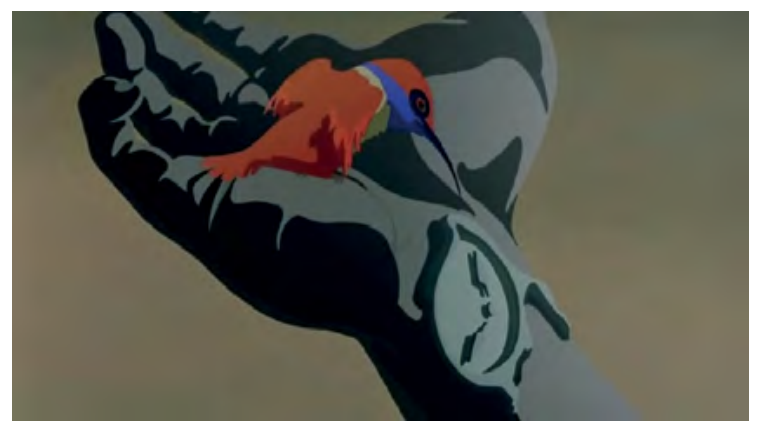

El colibrí picotea el reloj blando de pulsera que lleva en la muñeca la figura que se ha desprendido de la estatua.

Reloj esta vez de pulsera, porque se halla allí donde es posible sentir todavía el pulso, el latido mismo de la vida.

Las agujas, de hecho, comienzan a moverse. Cobran vida.

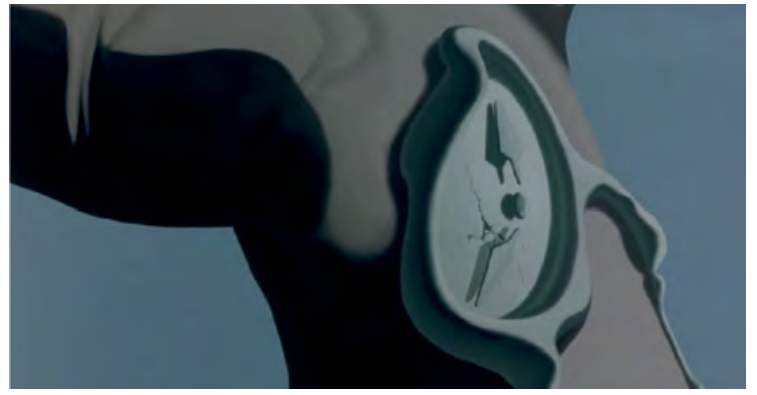

Persiste, no obstante, la simetría de las manecillas, que es la misma de las de dos gotas de agua que tanto se parecen: «nos parecíamos como dos gotas de agua», confesaba Salvador Dalí, el artista.

La hora marcada son las siete menos cinco, exactamente la misma de Osificación prematura de una estación.

De la palma de la mano empiezan a salir hormigas que se transforman de inmediato en bicicletas.

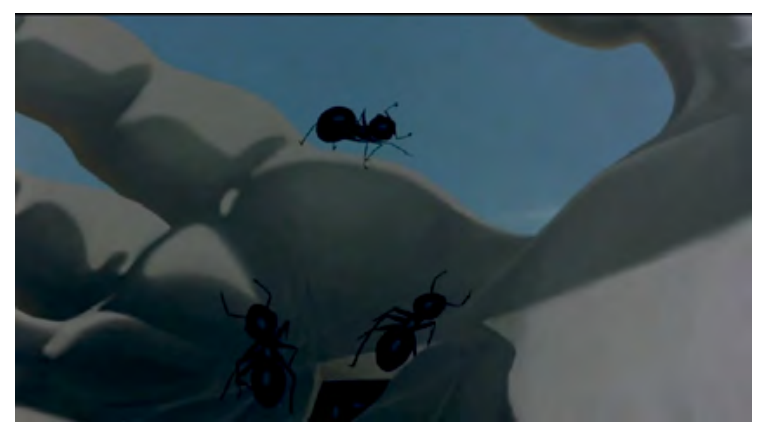

La sensación de hormigueo, tan presente en la obra pictórica de Dalí, está asociada a ese momento en que cierta parte del cuerpo que se había quedado dormida - una pierna, un brazo, una mano...-, comienza a despertarse.

Un ejército de hombres hormiga monta en bicicletas cuyo manillar tiene forma de muleta y lleva sobre sus cabezas, como diligentes hormigas, un trocito de pan. 


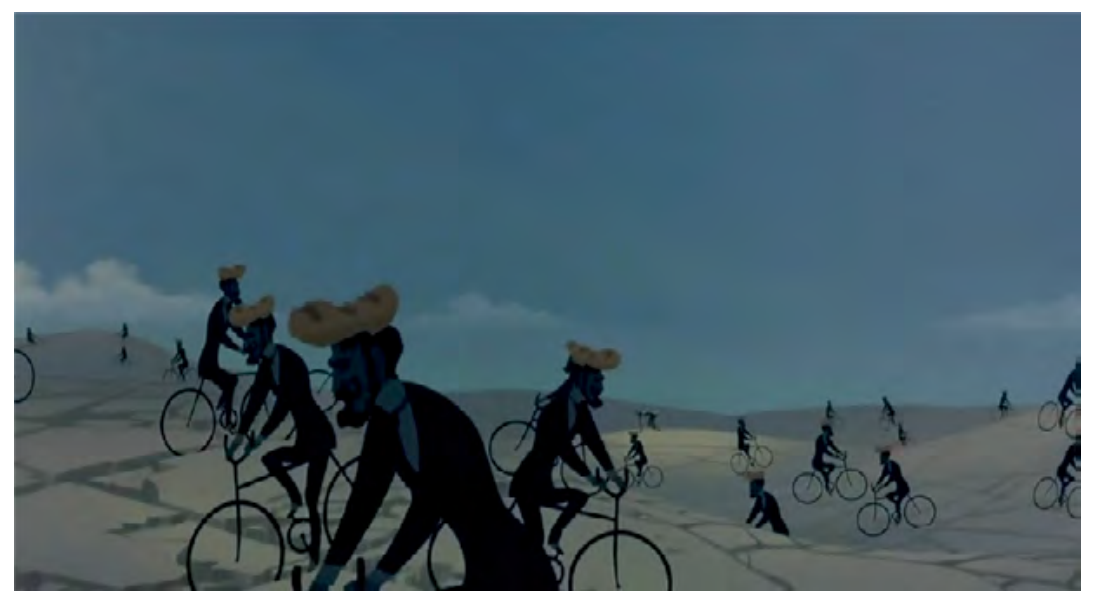

En su obra Pan antropomórfico, Dalí pinta un pan con forma humana semejante a los que llevan sobre sus cabezas esos hombres-hormiga que pedalean incansables. Sobre ese pan cuelga un reloj blando, más derretido que ningún otro, que parece marcar las seis en punto. Bastaría con que la manecilla larga, la del minutero, cayese —o se derritiese- para que la hora marcada fuera de nuevo la hora más temida, o tal vez la más deseada: las seis y media.

Una cuerda con forma de muleta ayuda a que el pan con forma antropomórfica del que cuelga el reloj blando, consiga alzarse aunque sea levemente.

\section{Referencias}

DALí, Salvador. Vida secreta de Salvador Dalí.

Barcelona: Empúries, 1993.

\section{FICHA TÉCNICA}

Título: Destino

Título original: Destino

País: Francia y USA.

Año: 2003.

Director: Dominique Monfery.

Música: Armando Domínguez.

Montaje: Jessica Ambinder-Rojas.

Guion: Salvador Dalí, John Hench.

Intérpretes: Jennifer Esposito, Dora Luz (voces).
Color: color (animación)

Duración: 7 minutos.

Género: animación, fantástico, surrealismo.

\section{SINOPSIS:}

«Destino» es un cortometraje de animación de 7 minutos de duración que Walt Disney le encargó a Salvador Dalí en 1948, y que está basado en la canción Destino, del mexicano Armando Domínguez. Tenía que combinar ballet y dibujos, y debía formar parte de un largometraje de relatos breves, pero el proyecto quedó inconcluso tras 20 segundos realizados. Hasta el año 2003 no se retomó el proyecto, mucho después del fallecimiento de ambos, y gracias a los bocetos e instrucciones que había dejado el propio Dalí.

\section{PREMIOS:}

Oscars: Nominado en 2003 al mejor cortometraje de animación.

\section{PRODUCTORA:}

Walt Disney Feature Animation/Walt Disney Pictures/ Disney Studios France.

\section{ENLACES:}

https://www.imdb.com/title/tt0377770/ https://www.filmaffinity.com/es / film123105.html 
